SCIREA Journal of Energy

http://www.scirea.org/journal/Energy

March 29, 2021

Volume 6, Issue 1, February 2021

SCIREA

\title{
Matrix Converter-Based Current Predictive Control of Novel Power Electronic Transformer
}

\author{
Yougui Guo, Bowen Yang, Liyang Duan, Wenlang Deng \\ Xiangtan University, Xiangtan, China \\ Email: 719983182@qq.com (Yougui Guo), 1219684412@qq.com (Bowen Yang), \\ 499895506@qq.com (Liyang Duan),Dengwenl@sohu.com (Wenlang Deng)
}

\begin{abstract}
In this paper, the predictive current control is applied to the matrix converter-based novel power electronic transformer(MC-NPET). In order to control the output voltage, PI control is added. The proposed method aims to regulate the output voltage of the novel power electronic transformer and correct the input power factor. By discretizing the input and output model of novel power electronic transformer to predict the value of the controlled variables at the next time. By using a predictive cost function, the best switch combinations to be applied to the next time. The proposed cost function takes both the output current and the input power factor into account. This paper also analyzes the stability of the system and analyzes the system output voltage under different load conditions. Finally use MATLAB/Simulink to verify the method.
\end{abstract}

Keywords: Model predictive control, Matrix converter-based novel power electronic transformer, Voltage control, Power factor

Supported by Key Projects(20A478) of Educational Commission of Hunan Province of China 


\section{Introduction}

As a kind of AC-AC direct conversion device, the matrix converter has drawn more and more attention in recent years. Compared with the traditional AC-DC-AC converter, it eliminates the middle of the DC link and reduce the size of the converter [1]. Matrix converter also has other advantages such as: featuring sinusoidal input/output currents [2], [3], the input power factor can be adjusted, the energy can flow in both directions [4]. Because of these advantages that matrix converters are used in a variety of applications, such as wind power, power electronic transformer and motor control [5].

In this paper, the main functions of the proposed converter are to ensure that the output voltage meets the requirements and to adjust the input power factor [6]. The proposed MCNPET as shown in Fig. 1. As can be seen from Figure 1, MC-NPET mainly consists of a matrix converter, two power transformers. The power transformer $\mathrm{T}_{\mathrm{S} 1}$ adjusts the voltage on the MV side, and then the voltage on the power transformer $\mathrm{T}_{\mathrm{S} 2}$ can be changed by controlling the output voltage of the matrix converter to achieve the effect of controlling the voltage on the LV side. There is a filter circuit at the input of the matrix converter to ensure the stability of the input voltage and the quality of the input current, reducing the input harmonic content [7]. There are two types of loads that will be used on the LV side, namely resistive load and back EMF load.

Compared with the traditional MC topology, MC-NPET has a larger voltage range, the output voltage harmonic content is lower, the output waveform is almost no distortion, the input side power factor can reach the unit value [4]. The combination of a transformer and a matrix converter can reduce the value of the current in the matrix converter by adjusting the transformer's ratio, thereby reducing switching losses and overall system cost.

Matrix converters contain a lot of switches, so the mathematical model is complex, making modulation methods and commutation control cumbersome. The stability and reliability are not ideal, so the matrix converter control strategy is much more complicated than the traditional AC-AC converter and inverter. In the past few decades, a variety of matrix converter control strategies have been proposed [8], from the earliest Venturini method, then the optimized A-V method, and then the space-vector modulation (SVM). Space vector modulation is the most commonly used at present. However, the biggest problem with space vector modulation is that it requires the construction of complex mathematical models. The accuracy of the model directly determines the quality of the control. So in order to make up 
for the shortcomings of SVM, a new control method needs to be proposed. As a new control strategy, model predictive control (MPC) has developed rapidly in recent years. It has been proved in many applications that MPC has better control effects and can better utilize the performance of the microprocessor [9]-[11]. Compared with SVM, MPC model is easier to build, the concept is intuitive and easy to understand, multi-objective optimization can be realized, and it is easier to apply on the microcontroller [12]. Moreover, in the unit sampling time, only one switch combination needs to be applied, which reduces the switching time of the switch, so the sampling frequency of the system can be improved, thereby improving the control effect. MPC is to build a system model to predict the change of variables in the next cycle. And choose an optimal option from all the changes to minimize the cost function. Predictive current control (PCC) can be considered as a specific application of MPC. In the matrix converter, the predictive current control can be expressed as : First, Using the input and output filter circuit of matrix converter to build the input and output current prediction model. Second, the cost function is constructed by combining the reference value of the current with the prediction model. Third, bring the 27 switch combinations into the prediction model to get the current prediction value and choose a switch combination which can minimize cost function. Finally, apply the selected switch combination to the next cycle of the matrix converter [13]. In the matrix converter, the function of the cost function is to define the expected value of the variable, so both the input power factor and the output current must be considered. This is also the advantage of MPC, which can represent the expected value of all variables with one cost function.

In order to verify the stability of the system, the stability analysis of the system was performed using the Rolls criterion in this paper. In order to verify the dynamic performance of the system, the MV side voltage swell and sag were added to the simulation model. And use simulation to analyze the output voltage when the output of the system is connected to the resistive load and the back EMF load.

In this paper, the PCC is apply to MC-NPET. The main control objects are the input power factor on the MV side and the voltage on the LV side. And through simulation and experiment to verify the control strategy proposed in this paper. This paper is organized as follows. Section II presents the fundamental of matrix converter. Section III shows the predictive model of MC-NPET. Section IV shows the control strategy of the MC-NPET. Section V is the system stability analysis. Section VI is the simulation and experimental results. Section VII draws the conclusion. 


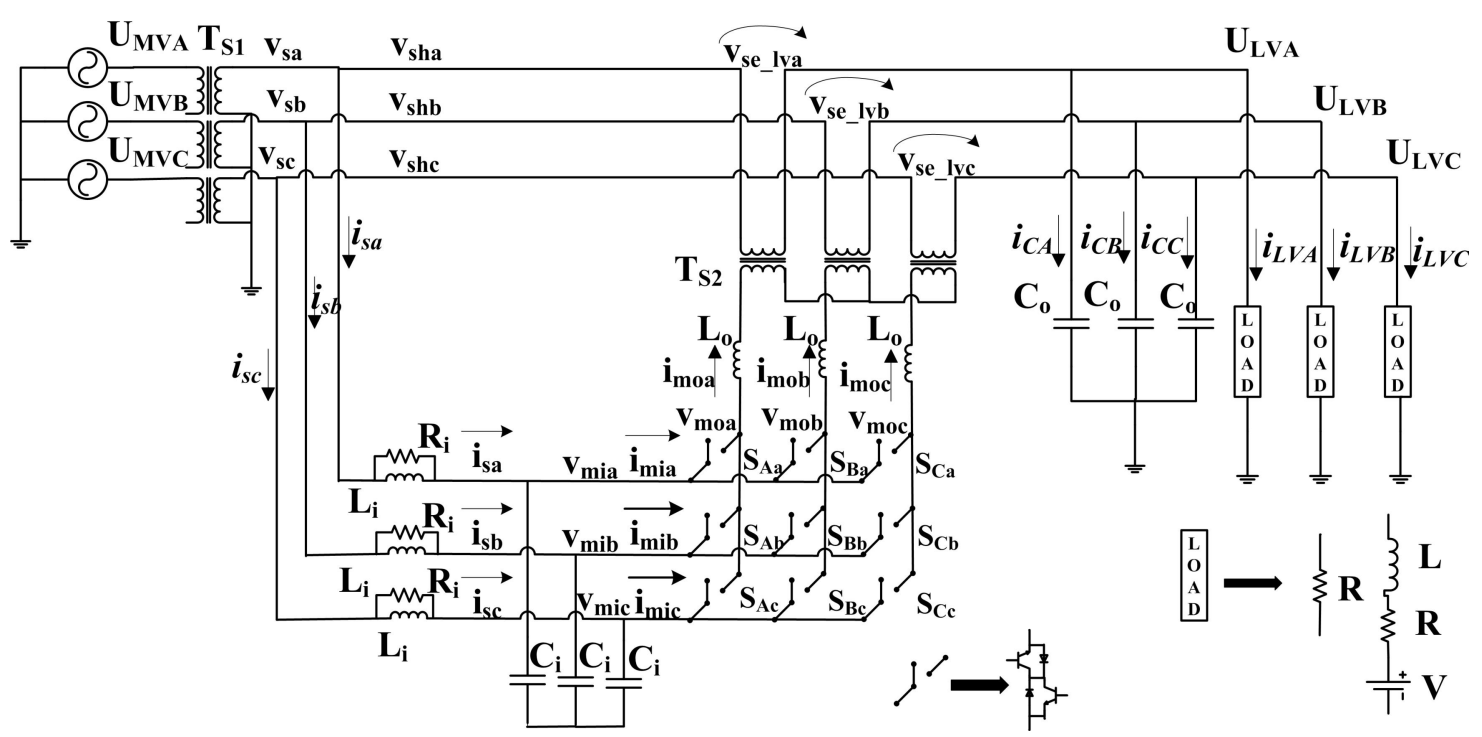

Fig. 1. Matrix Converter-based Novel Power Electronic Transformer

\section{Fundamental of Matrix Converter Model}

\section{A. Matrix Converter}

This paper is used in three-phase to three-phase matrix converter, its topology presented in Fig. 1. The matrix converter can be seen as an array of 9 bidirectional switches. The array input to the array is a three-phase supply and the output is connected to a three-phase load. Each bidirectional switch consists of two IGBTs and two diodes as shown in Fig. 1.

Each bidirectional switch in the matrix converter can be represented by the switch function $S_{i, j}(i, j \in\{1,2,3\})$. The function should be defined as follows:

$$
S_{i j}(t)=\left\{\begin{array}{lll}
1, & S_{i j} & \text { closed } \\
0, & S_{i j} & \text { open }
\end{array} \quad i \in\{A, B, C\}, j \in\{a, b, c\}\right.
$$

In the working process, the matrix converter must comply with two principles: 1) Any twophase of input can not be short-circuited; 2) Any output phase can not be disconnected. It can be written as follows [14],

$$
S_{i a}+S_{i b}+S_{i c}=1 \quad i \in\{A, B, C\}
$$

According to (2), the matrix converter has a total of 27 kinds of switch combinations.

The relationship between input voltages $\left(V_{a} V_{b} V_{c}\right)$ and output voltages $\left(V_{A}, V_{B}, V_{C}\right)$ are as follows: 


$$
\left[\begin{array}{l}
v_{A} \\
v_{B} \\
v_{C}
\end{array}\right]=\left[\begin{array}{lll}
S_{A a} & S_{A b} & S_{A c} \\
S_{B a} & S_{B b} & S_{B c} \\
S_{C a} & S_{C b} & S_{C c}
\end{array}\right] *\left[\begin{array}{l}
v_{a} \\
v_{b} \\
v_{c}
\end{array}\right]
$$

The relationship between output currents $\left(\begin{array}{lll}i_{A} & i_{B} & i_{C}\end{array}\right)$ and input currents $\left(\begin{array}{lll}i_{a} & i_{b} & i_{c}\end{array}\right)$ are as follows:

$$
\left[\begin{array}{l}
i_{a} \\
i_{b} \\
i_{c}
\end{array}\right]=\left[\begin{array}{lll}
S_{A a} & S_{B a} & S_{C a} \\
S_{A b} & S_{B b} & S_{C b} \\
S_{A c} & S_{B c} & S_{C c}
\end{array}\right] *\left[\begin{array}{l}
i_{A} \\
i_{B} \\
i_{C}
\end{array}\right]
$$

\section{Predictive Control Model of MC-NPET}

The detailed topology of MC-NPET is given in Figure. 1. According to the input and output filter circuit of MC-NPET in Figure. 1, the MC-NPET 's prediction control model can be built.

\section{B. Input Filter Model}

From the Fig. 1, the equations of input filter model can be expressed as follows:

$$
\begin{aligned}
& v_{S}(t)=L_{i} \frac{d i_{L_{i}}(t)}{d t}+v_{m i}(t) \\
& i_{L_{i}}(t)=i_{S}(t)-\frac{v_{S}(t)-v_{m i}(t)}{R_{i}}
\end{aligned}
$$

Because the system sampling frequency is very high, within the unit sampling period, $v_{s}(t)$, $v_{m i}(t)$ can be regarded as a constant value, so the combination of (6), (5) can be rewritten as follows:

$$
\begin{aligned}
& v_{s}(t)=L_{i} \frac{i_{s}(t)}{d t}+v_{m i}(t) \\
& i_{s}(t)=i_{m i}(t)+C_{i} \frac{d v_{m i}(t)}{d t}
\end{aligned}
$$

Rewritten (7) and (8) into the state space model:

$$
\frac{d x(t)}{d t}=A[x(t)]+B[u(t)]
$$

Where,

$$
\mathrm{A}=\left[\begin{array}{cc}
0 & \frac{1}{C_{i}} \\
-\frac{1}{L_{i}} & 0
\end{array}\right] \quad \mathrm{B}=\left[\begin{array}{cc}
0 & -\frac{1}{C_{i}} \\
\frac{1}{L_{i}} & 0
\end{array}\right] \mathrm{x}(\mathrm{t})=\left[\begin{array}{c}
v_{m i} \\
i_{s}
\end{array}\right] \mathrm{u}(\mathrm{t})=\left[\begin{array}{c}
v_{s} \\
i_{m i}
\end{array}\right]
$$


When the sampling period is expressed as $T_{s}$. And (9) can be written as the discrete-time state space model as follows:

$$
\left[\begin{array}{c}
v_{m i}[k+1] \\
i_{s}[k+1]
\end{array}\right]=G\left[\begin{array}{c}
v_{m i}[k] \\
i_{s}[k]
\end{array}\right]+H\left[\begin{array}{c}
v_{s}[k] \\
i_{m i}[k]
\end{array}\right]
$$

Where [15],

$$
\begin{aligned}
& \mathrm{G}=e^{A^{*} T_{s}}=\left[\begin{array}{ll}
G_{11} & G_{12} \\
G_{21} & G_{22}
\end{array}\right] \\
& \mathrm{H}=\int_{0}^{T_{s}} e^{A\left(T_{s}-\tau\right) *} B d \tau=\left[\begin{array}{ll}
H_{11} & H_{12} \\
H_{21} & H_{22}
\end{array}\right]
\end{aligned}
$$

So, the next time value of input current can be predicted as follows:

$$
i_{s}[k+1]=G_{21} \cdot v_{m i}[k]+G_{22} \cdot i_{s}[k]+H_{21} \cdot v_{s}[k]+H_{22} \cdot i_{m i}[k]
$$

\section{Load Model}

Considering the topology of MC-NPET from Fig. 1, the equation for the load can be expressed as follows:

$$
v_{m o}(t)=L_{o} \frac{d i_{m o}(t)}{d t}+v_{s e}(t)
$$

In (15), $\frac{d i_{m o}(t)}{d t}$ can be approximately expressed as:

$$
\frac{d i_{m o}}{d t} \approx\left\{I_{o}(k+1)-I_{o}(k)\right\} / T_{S}
$$

Combined with (15) and (16), the predicted value of the output current can be expressed as:

$$
I_{o}(k+1)=v_{m o}(t) * \frac{T_{s}}{L_{o}}-v_{s e}(t) * \frac{T_{s}}{L_{o}}+I_{o}(k)
$$

\section{Cost Function}

The control scheme of MC-NPET can be shown in Fig. 2. At each sampling period, the current $i_{s}$ and output current $i_{m o}$ are calculated by the measured values. When choosing the switch combinations of the matrix converter, we can not only consider the output constraints, but also consider the constraints of the input power factor. In order to satisfy all of the above conditions, we use the cost function as follows:

$$
\begin{gathered}
g=g_{1}+\lambda g_{2} \\
g_{1}=\left|i_{\text {moaref }}^{k+1}-i_{\text {moa }}^{p}(k+1)\right|+\left|i_{\text {mobref }}^{k+1}-i_{\text {mob }}^{p}(k+1)\right|+\left|i_{\text {mocref }}^{k+1}-i_{\text {moc }}^{p}(k+1)\right|
\end{gathered}
$$




$$
g_{2}=\lambda\left|v_{s \alpha}{ }^{*} i_{s \beta}^{p}(k+1)-v_{s \beta} * i_{s \alpha}^{p}(k+1)\right|
$$

Where, $i_{\text {moaref }}^{k+1}, i_{\text {mobref }}^{k+1}, i_{\text {mocref }}^{k+1}$, are the reference output current and $i_{\text {moa }}^{p}(k+1), i_{\text {mob }}^{p}(k+1)$, $i_{m o c}^{p}(k+1)$, are the predicted output current. $v_{s \alpha}, v_{s \beta}$ are the values of source voltages and $i_{s \beta}^{p}(k+1), i_{s \alpha}^{p}(k+1)$ are the predicted input current.

$g_{1}$ is the constraints of the output current. The predicted value of the output current is compared with the reference value. By selecting the appropriate switch combination to make the output current tracking reference current better. $g_{2}$ is the constraints of the input power factor. Through the coordinate conversion, changing the input voltages $v_{s a}, v_{s b}, v_{s c}$ into $v_{s \alpha}$, $v_{s \beta}$ and changing the predicted input current $i_{s a}^{p}(k+1), i_{s b}^{p}(k+1), i_{s c}^{p}(k+1)$ into $i_{s \beta}^{p}(k+1)$, $i_{s \alpha}^{p}(k+1) . \lambda$ is the weighting factors which determine for the term. The smaller input reactive power, the input power factor closer to the unity power factor. The equation of reactive power is as follows [16]:

$$
Q=v_{\alpha}{ }^{*} i_{\beta}-v_{\beta}{ }^{*} i_{\alpha}
$$

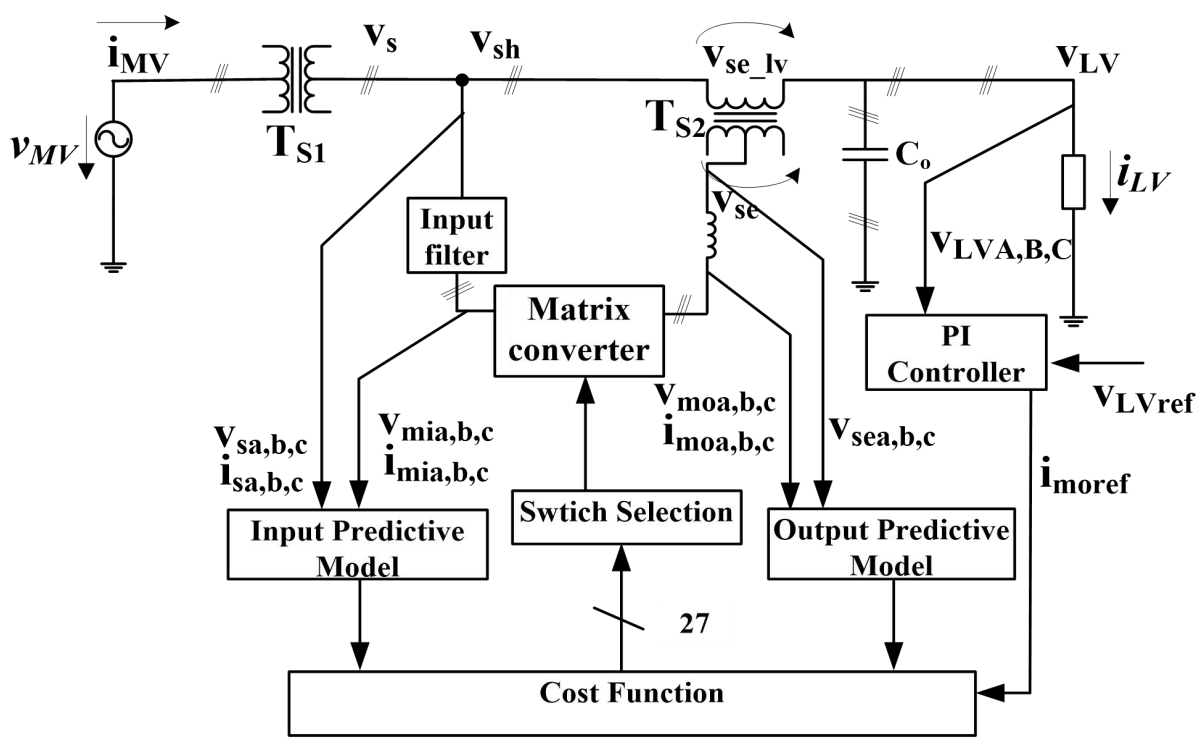

Fig. 2. Control scheme of MC-NPET

\section{Control of The MC-NPET}

The predictive current control flow chart of MC-NPET as shown Fig. 3. The function of model predictive control strategy is to control the input power factor and output current of the 
matrix converter. In order to control the voltage of the LV side, the PI controller is added. So the whole control system is divided into two control links, the outer loop is LV grid voltages control, and the inner loop is current control.

\section{E. Input Current and Output Current control}

From the previous section, it is can be seen that the focus of input power factor and output current control is the cost function. Cost function is built on the basis of input current prediction model and output current prediction model.

The predicted value of input current $i_{s}[k+1]$ needs to take the values of $i_{m i}$ and the measured values of $v_{m i}, v_{s}, i_{s}$ into the prediction model for calculation. The constraints of the input power factor in the cost function was established by the predicted current $i_{s}[k+1]$ and input voltage $v_{s}$. Because there are 27 kinds of switch combinations in matrix converter, and the value of $i_{m i}$ is determined by the value of $i_{m o}$ in each switch combination. So, there are 27 possibilities in the value of $i_{m i}$ and $i_{s}[k+1]$.

The predicted value of output current $I_{o}(k+1)$ needs to take the values of $v_{m o}$ and the measured values of $v_{s e}, I_{o}$ into the prediction model for calculation. The constraints of the input power factor in the cost function was established by the predicted current $I_{o}(k+1)$ and output reference current $i_{\text {moref }}^{k+1} . v_{m o}$ and $i_{m i}$ are similar. The $v_{m o}$ value is determined by the value of $v_{m i}$ in each of 27 switch combinations. So, there are also 27 possibilities in the value of $v_{m o}$ and $I_{o}(k+1)$.

Cost function considers both input power factor and output current. The ratio between the input power factor and output current is determined by $\lambda$. After determining the model, we need to constantly adjust the value of $\lambda$, in order to make the input and output meet the requirements at the same time. After determining the cost function, it is necessary to select one of the 27 switch combinations to make cost function minimum.

\section{F. Control of the LV Grid Voltages}

Predictive control model is only used to control input power factor and output current. So in order to control LV grid voltages to achieve reference standard, PI controller is added. The control block diagram of the LV grid voltages is shown in Figure. 4. The value of the difference between the reference voltage and the actual voltage is adjusted by the PI regulator, and the result as the reference value of the output current. 


\section{G. Control of the Input Power Factor}

Before the power factor correction is added to the MV side, the voltage and current vector of the system are shown in the Figure. 5. There is phase difference between the current and voltage on the LV side, and there is the same phase difference between voltage and the current on the MV. Therefore, in order to correct the power factor of the MV side and make the power factor of the MV side close to the unit value, it is necessary to measure the phase angle $\beta$ between the $v_{l v}$ and $i_{l v}$ and add it to the reference voltage of the $v_{l v}$. After adding the power factor correction, the voltage and current vector on the MV side are shown in the Figure. 6.

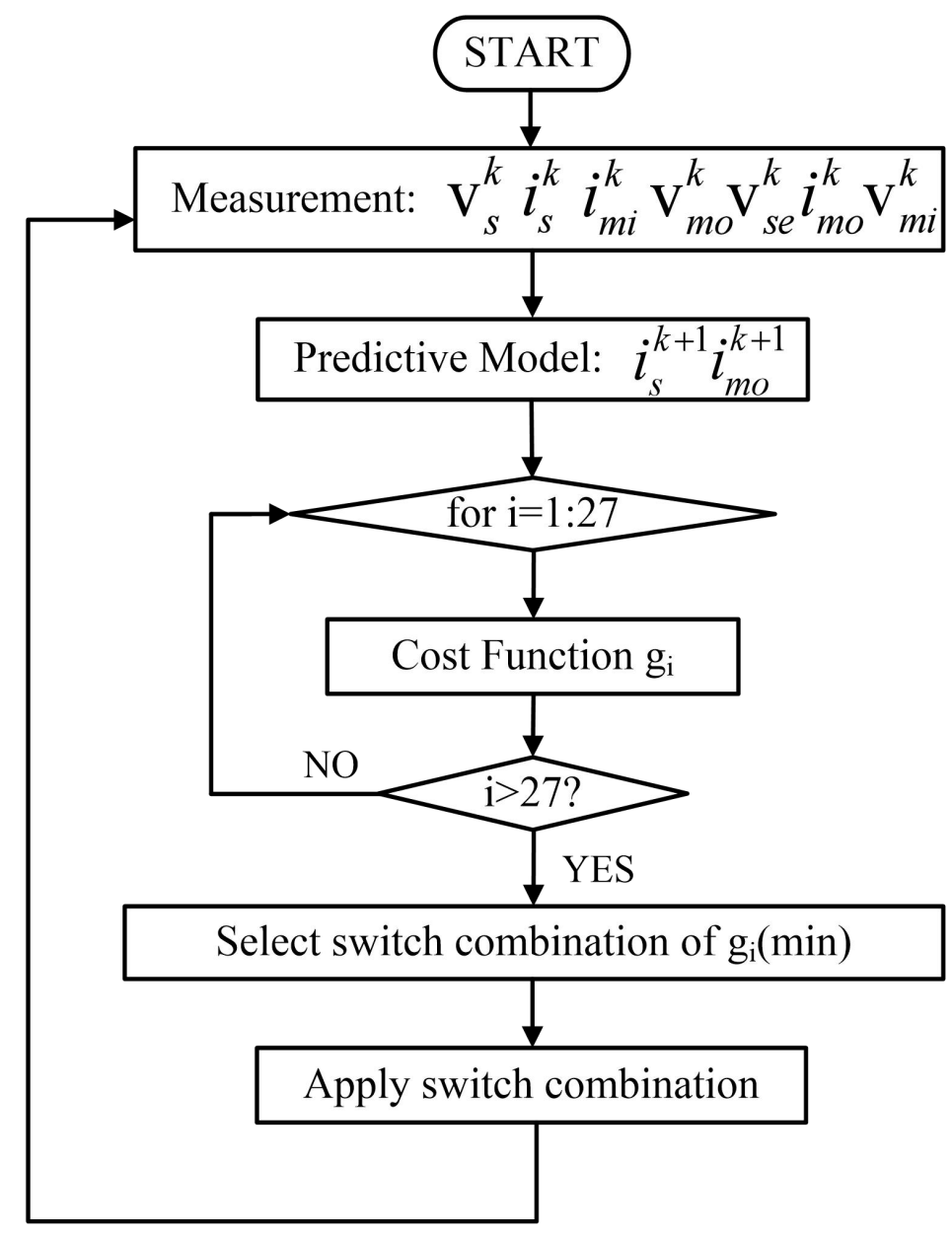

Fig. 3. Predictive current control flow chart of MC-NPET 


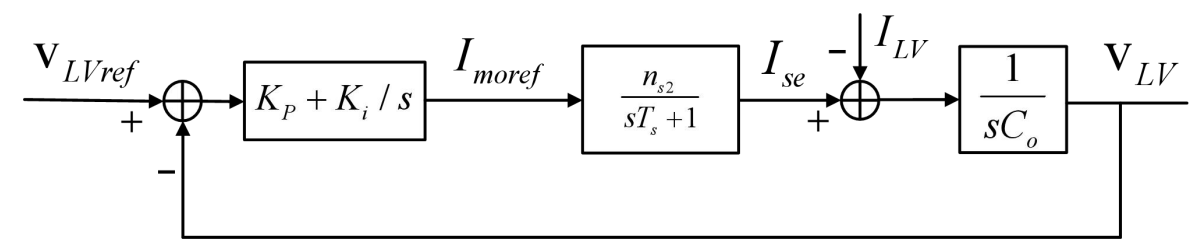

Fig. 4. The control block diagram of the LV grid voltages

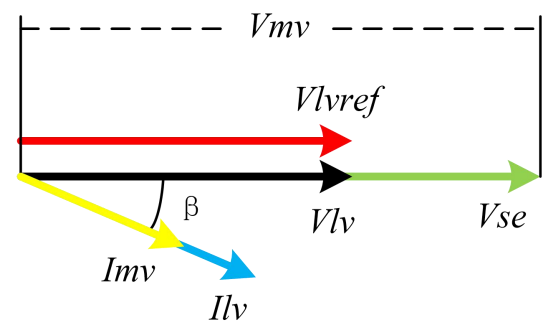

Fig. 5. The control block diagram of the LV grid voltages

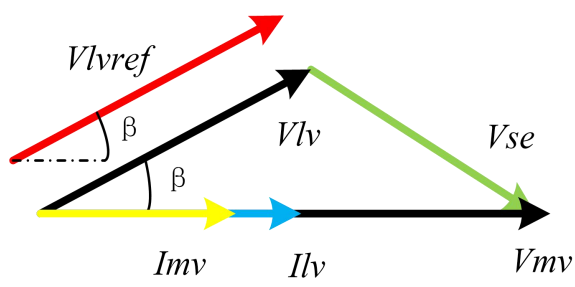

Fig. 6. The control block diagram of the LV grid voltages

\section{System stability analysis}

As shown in Figure 4, the transfer function of the system is as follows:

$$
\frac{\mathbf{v}_{\mathbf{L V}}}{\mathbf{v}_{\mathrm{LVref}}}=\frac{\mathbf{K}_{\mathbf{p}}{ }^{*} \mathbf{n}_{\mathbf{s}}{ }^{*} \mathbf{S}+\mathbf{K}_{\mathrm{i}}{ }^{*} \mathbf{n}_{\mathbf{S} 2}}{\mathbf{T}_{\mathbf{s}}{ }^{*} \mathbf{C}_{\mathbf{o}} \mathbf{S}^{3}+\mathbf{C}_{\mathbf{o}}{ }^{*} \mathbf{S}^{2}+\mathbf{K}_{\mathbf{p}} \mathbf{n}_{\mathbf{s} 2}{ }^{*} \mathbf{S}+\mathbf{K}_{\mathbf{i}}{ }^{*} \mathbf{n}_{\mathbf{s} 2}}
$$

Simplification:

$$
\frac{v_{L V}}{v_{L V r e f}}=\frac{K_{p}{ }^{*} n_{S 2}}{T_{S}{ }^{*} C_{o}} * \frac{S+\frac{K_{i}{ }^{*} n_{S 2}}{K_{p} n_{S 2}}}{S^{3}+\frac{1}{T_{S}} * S^{2}+\frac{K_{p} n_{S 2} *}{T_{S}{ }^{*} C_{o}} * S+\frac{K_{i}^{*} n_{S 2}}{T_{S} C_{0}}}
$$

The closed loop characteristic equation of the system is as follows:

$$
S^{3}+\frac{1}{T_{s}} * S^{2}+\frac{K_{p}{ }^{*} n_{s 2}}{T_{s}{ }^{*} C_{o}} * S+\frac{K_{i}{ }^{*} n_{S 2}}{T_{s}{ }^{*} C_{o}}=0
$$


where, $n_{S 2}=1, T_{s}=50 \mu s, C_{o}=200 \mu F, K_{p}=4, K_{i}=0.01$.

Using Routh criterion to analyze the stability of the system. The Routh array obtained from (24) is as follows:

$$
\begin{array}{cccc}
S^{3} & 1 & 4 * 10^{8} & 0 \\
S^{2} & 2 * 10^{4} & 4 * 10^{6} & 0 \\
S^{1} & 4 * 10^{8}-2 * 10^{2} & 0 & 0 \\
S^{0} & 4 * 10^{6} & 0 & 0
\end{array}
$$

It can be seen from the characteristic equation and the Routh array that all the coefficients of the characteristic equation are positive and the first element of the Routh array is positive, which satisfies the sufficient and necessary conditions for system stability. The zeros and poles distribution of the system is shown in Figure 7.

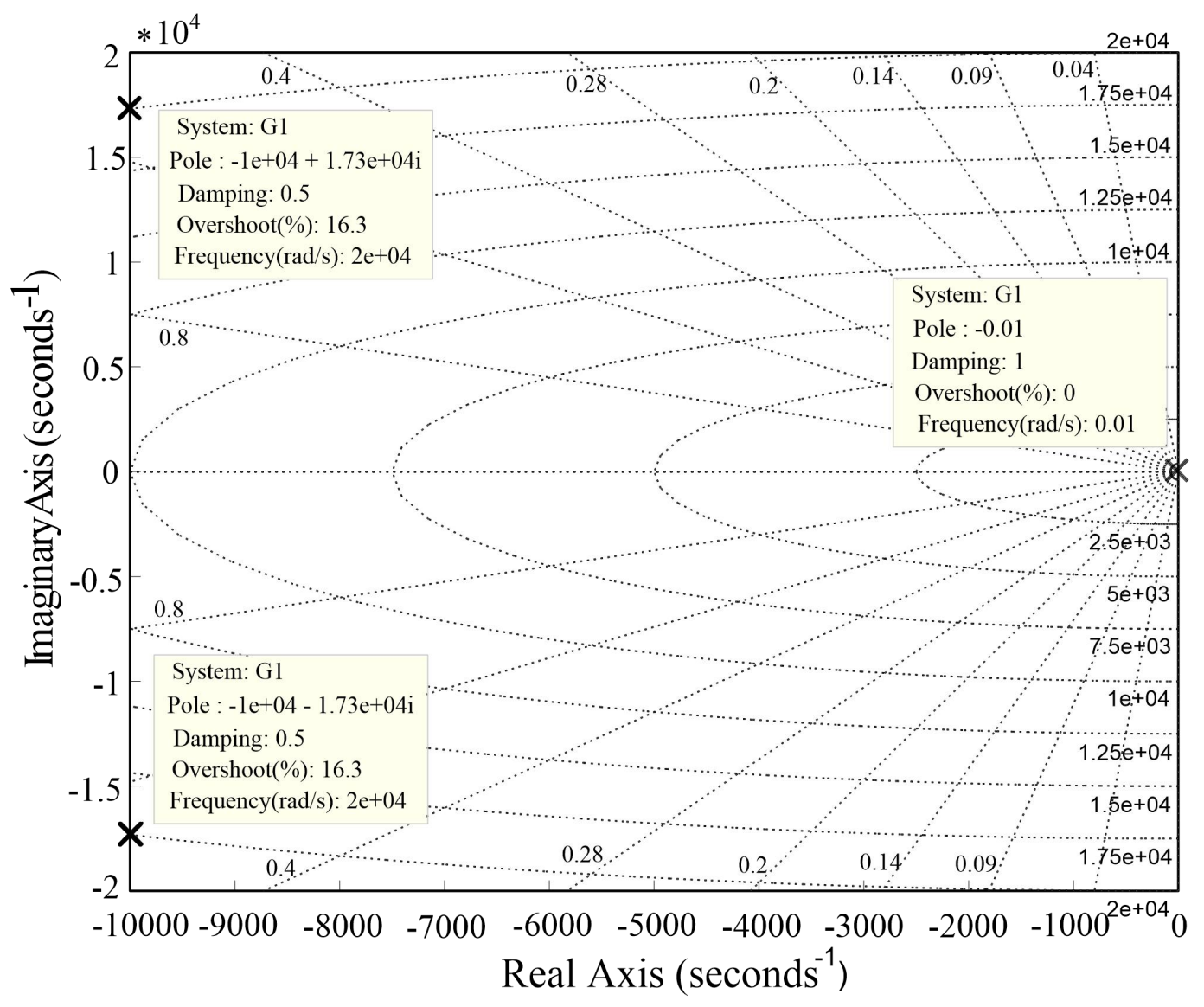

Fig. 7. Distribution of system zeros and poles 
As shown in Figure 7, the poles are all distributed on the negative half axis of the system, so the system is stable.

\section{Simulation and Experimental Results}

In this control model, because there are many parts such as input filter circuit, output filter circuit and matrix converter, Matlab/Simulink is used to build system simulation model. Because Matlab/Simulink is rich in function and simple in use, it can easily simulate the operation of the system under different conditions.

The parameters of simulation are as follows:

The amplitude of system input three-phase power is $220 \mathrm{~V}$, and the frequency is $50 \mathrm{H}_{Z}$. The turn ratio of transformer $T_{S 1}$ is $n_{S 1}=1$. The turn ratio of transformer $T_{S 2}$ is $n_{S 2}=1$. The parameters of the input side filter circuit of the matrix converter are $L_{i}=4.2 \mathrm{mH}, R_{i}=25 \Omega$, $C_{i}=6.6 \mu F$. The parameters of the output side filter circuit of the matrix converter are $L_{o}=6.5 \mathrm{mH}, R_{o}=20 \Omega, C_{o}=200 \mu \mathrm{F}$. The reference value of the LV grid voltage is $150 \mathrm{~V} / 50 \mathrm{~Hz}$. The system sampling period is $T_{s}=50 \mu \mathrm{s}$.

The simulation model is built according to the circuit topology of MC-NPET in Figure. 1 and the control principle in Figure 2.

Figures 8,9 , and 10 are simulation results of the system with resistive load. Figure. 8 shows the unfiltered waveform of the LV side voltage. Figure. 9 shows the filtered waveform of the LV side voltage. Figure 10 shows the result of FFT analysis of Ulva in Figure 9. Figures 11, 12, and 13 are simulation results of the system with Back EMF load. Figure. 11 shows the unfiltered waveform of the LV side voltage. Figure. 12 shows the filtered waveform of the LV side voltage. Figure 13 shows the result of FFT analysis of Ulva in Figure 12.

By comparing Figure 8 and Figure 11, before adding the filter, the LV side-connected back EMF load has a larger output voltage distortion and a much larger harmonic content than the resistive load. It can be seen from the comparison between Fig. 9 and Fig. 12 that when the output is connected to the resistive load and the back EMF load, after filtering, the output waveform is not much different. From Fig. 10 and Fig. 13, we can see that when the load is a back EMF load, only the harmonic content is slightly higher than the resistive load. Whether it is a resistive load or a back EMF load, the LV side voltage remains stable and meets the reference value. 
The waveform of LV grid voltages, se grid voltages and sh grid voltages in simulation are shown in Figure. 14. As shown in Figure. 14, sh grid voltages keeps steady. In space vector, the $v_{s h}=v_{s e}+v_{L V}$. Therefore, in order to ensure that LV grid voltages satisfies the reference value, the phase and amplitude of se grid voltages will be adjusted. It can be seen from Figure. 14 that the voltage of LV grid voltages is not overshoot, and it has reached stability in 0.01 seconds. The se grid voltages overshoot is very small, and it also achieves stability in 0.01 seconds. So, it can be seen that the system has a good effect on LV control.

The waveform of MV grid voltages, MV grid current are shown in Figure. 15 and Figure. 16. Fig. 15 is the waveform of the MV voltages and MV grid current without power factor correction. Fig. 16 showing the MV voltages and MV grid current with power factor correction. As can be seen from Fig. 15, when there is no power factor correction, there is a large deviation in the phase between MV voltages and MV grid current, so the MV side power factor is very low. In addition, from Figure. 16, power factor correction is added to $\mathrm{MV}$ voltages and MV grid current. It can be seen that MV voltages and MV grid current basically coincide in phase, and the power factor is close to 1. Satisfy the expectation.

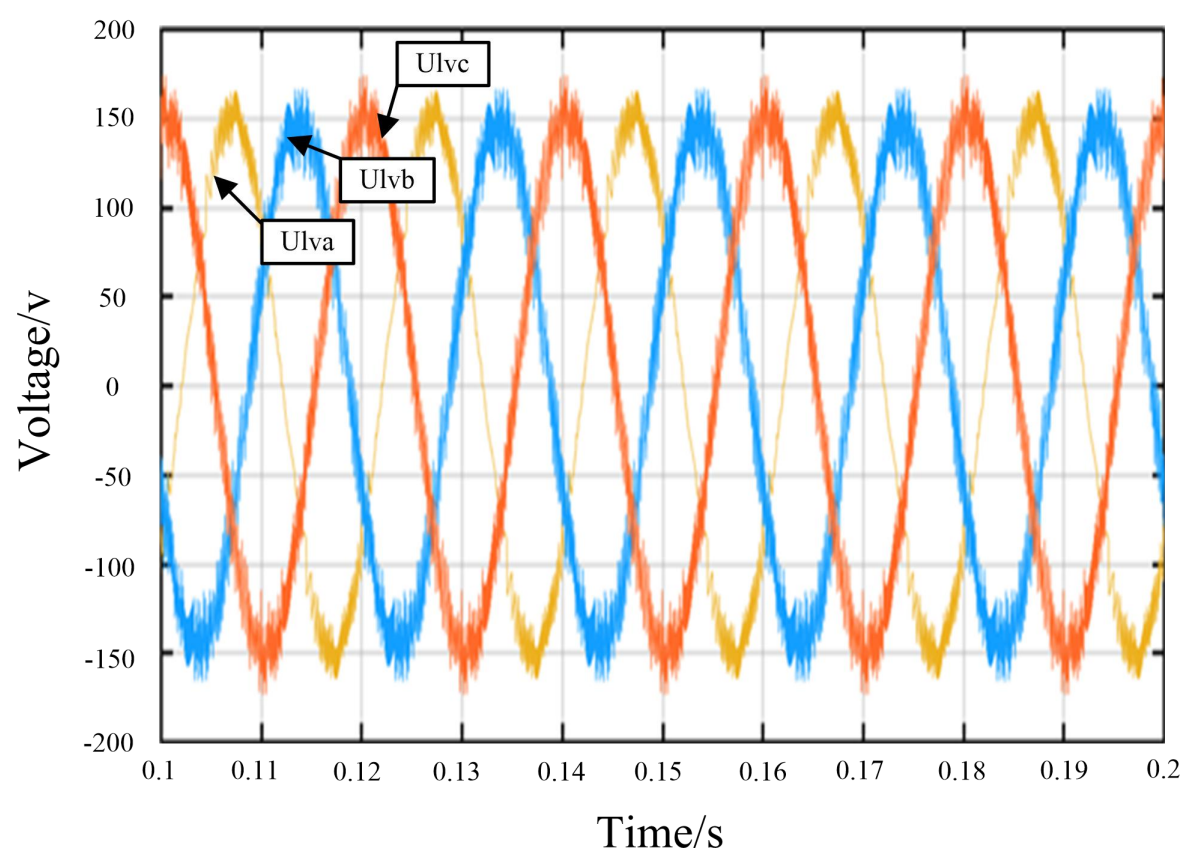

Fig. 8. The waveform of LV grid voltages without filtering(R load) 


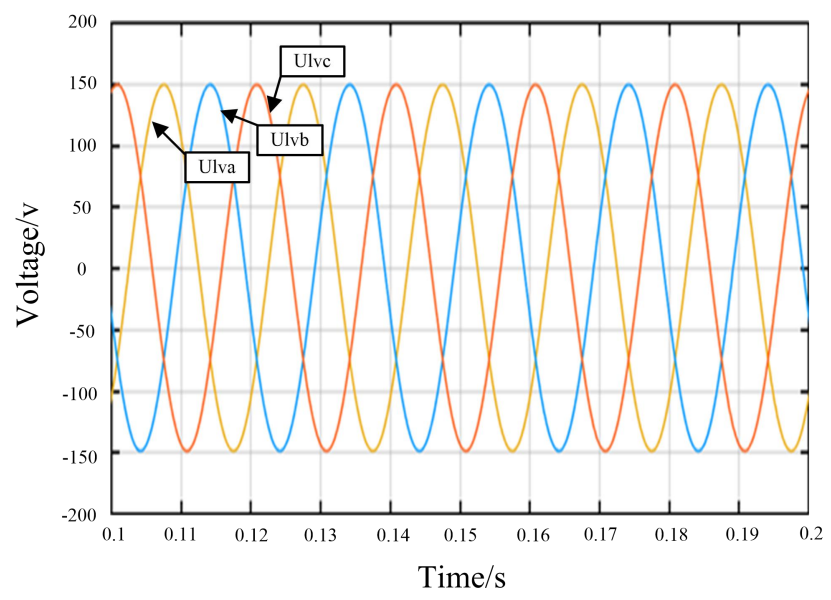

Fig. 9. The waveform of LV grid voltages after filtering( $\mathrm{R}$ load

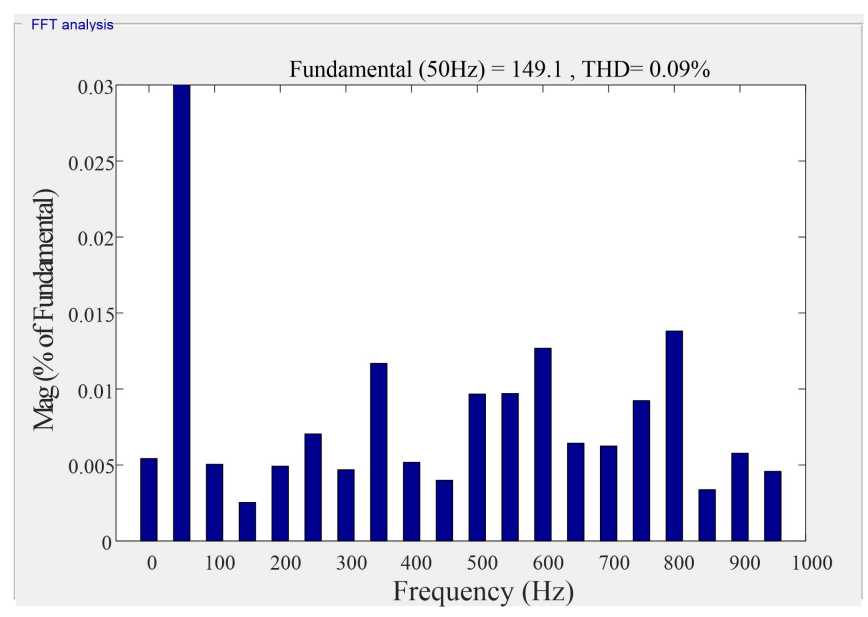

Fig. 10. The results of Ulva after FFT analysis(R load)

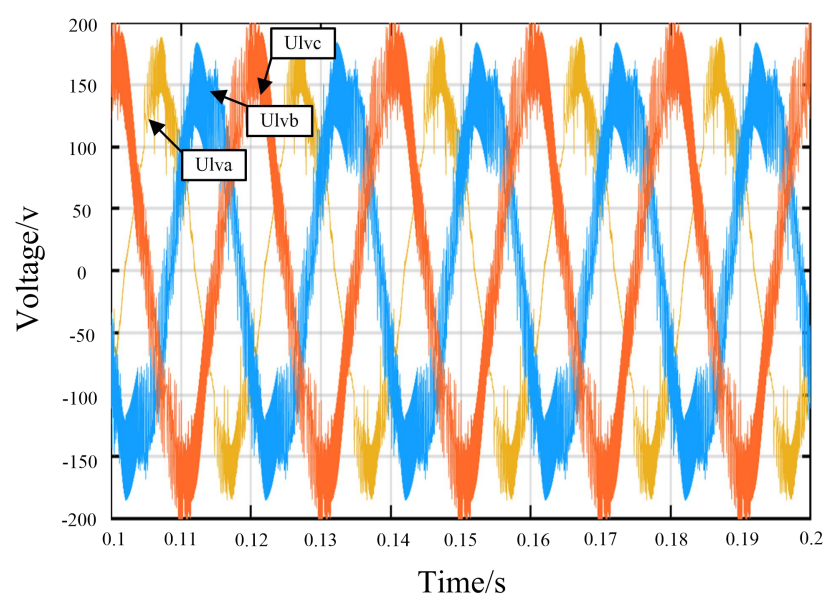

Fig. 11. The waveform of LV grid voltages without filtering(Back EMF load) 


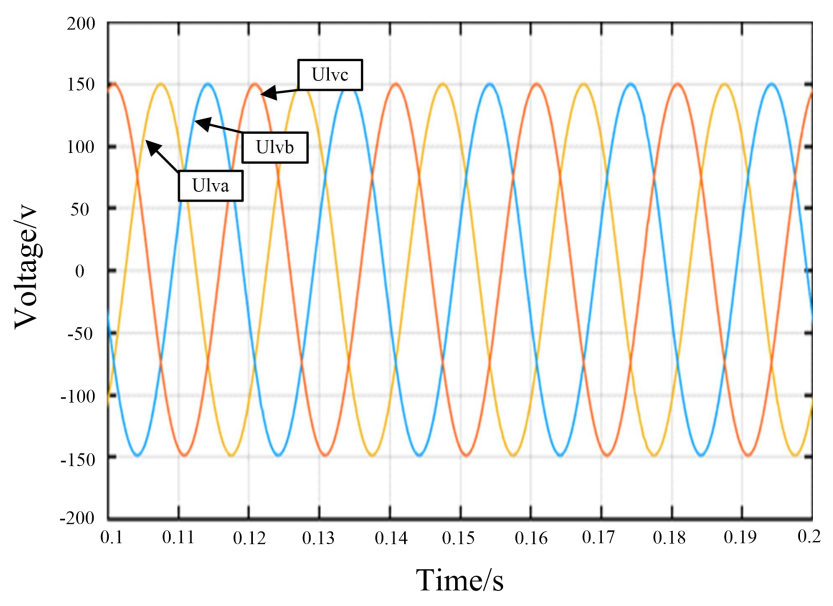

Fig. 12. The waveform of LV grid voltages after filtering(Back EMF load)

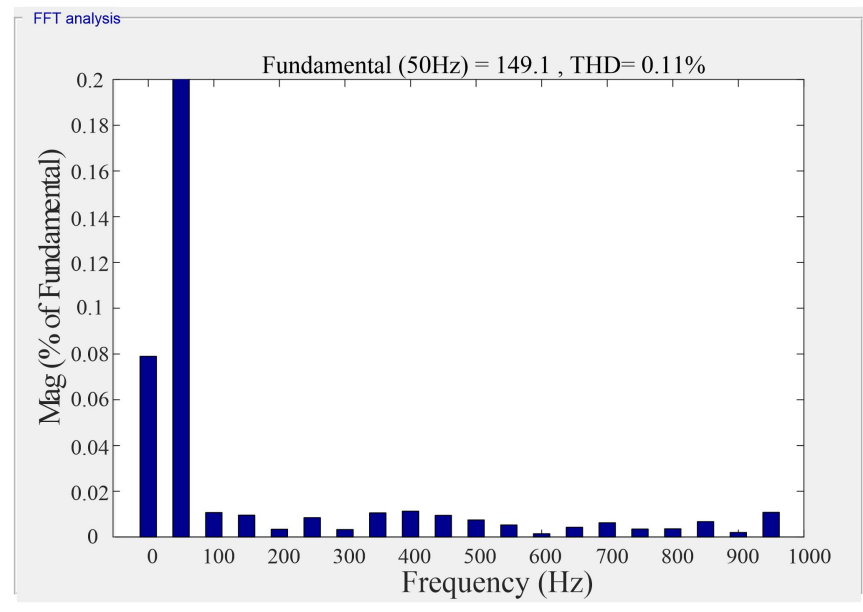

Fig. 13. The results of Ulva after FFT analysis(Back EMF load)

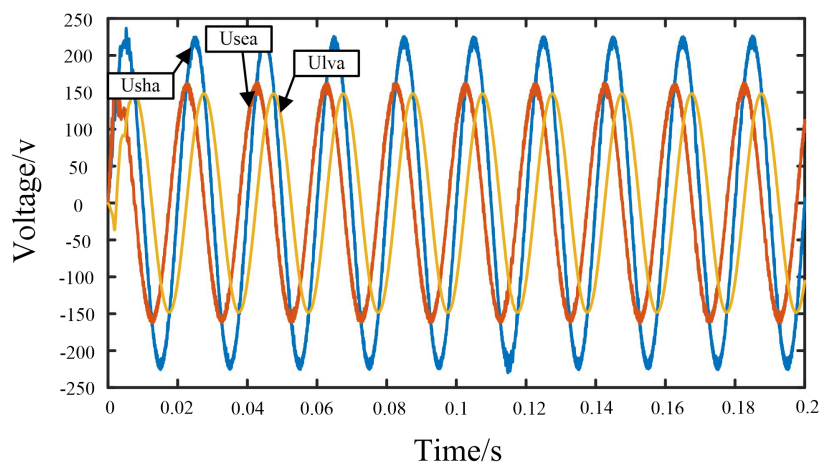

Fig. 14. The waveform of LV grid voltages, se grid voltages and $s h$ grid voltages 


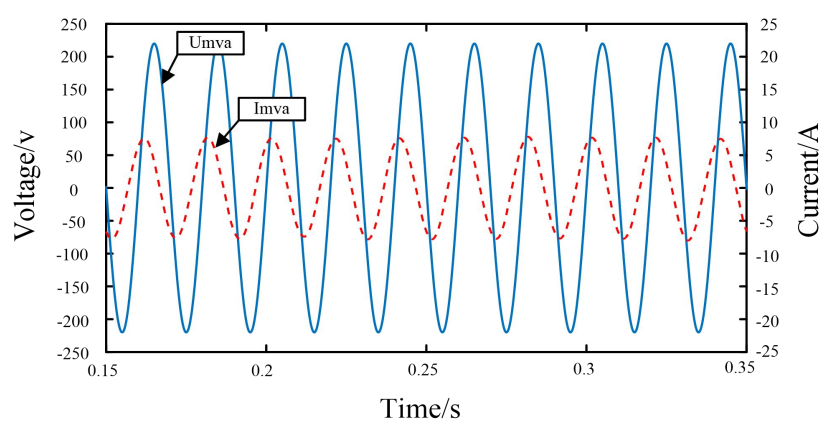

Fig. 15. The waveform of the MV voltages and MV grid current without power factor correction

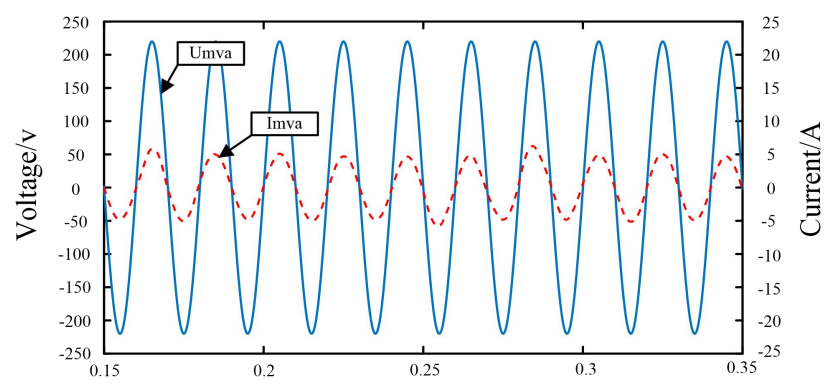

Fig. 16. The waveform of the MV voltages and MV grid current with power factor correction

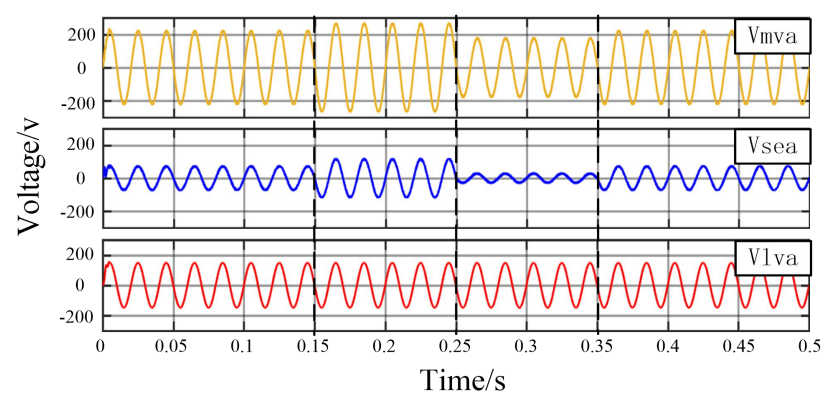

Fig. 17. The waveform of the MV, se and sh grid voltages

Figure. 17 shows the waveform of the voltage on the se side and the LV side when the voltage of the MV side changes abrupt. As can be seen from the Figure. 17, when the MV side voltage suddenly rises or falls, the system always adjusts the voltage on the se side in time to keep the voltage on the LV side stable.

In order to verify the correctness of the control strategy, an experimental platform was built based on MC-NPET topology. The experimental platform is shown in Figure. 18. The 
experimental platform mainly includes matrix converter, input and output filter circuit, controller, transformer and so on.

Unlike the simulation, the reference voltage of the experiment is $100 \mathrm{~V} / 50 \mathrm{~Hz}$.

The experimental waveforms are shown in Figure. 19, Figure. 20 and Figure. 21.

The waveform of the LV grid voltages is shown in Figure. 19. The voltage amplitude and frequency of the LV side are closely follow the reference voltage.

The Figure. 20 is the waveform of the MV voltages and MV grid current without power factor correction. The Figure. 21 is the waveform of the MV voltages and MV grid current with power factor correction. It can be seen from the Figure. 20 and Figure. 21 that after adding power factor correction, the power factor of the MV side has been greatly improved, which is close to 1 .

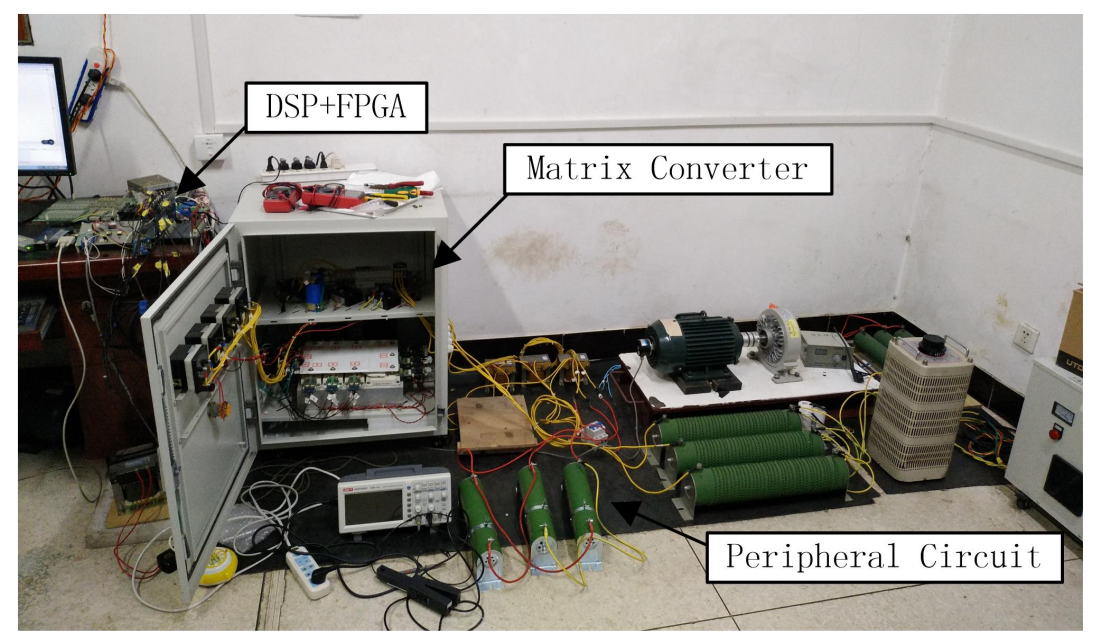

Fig. 18. Experimental platform

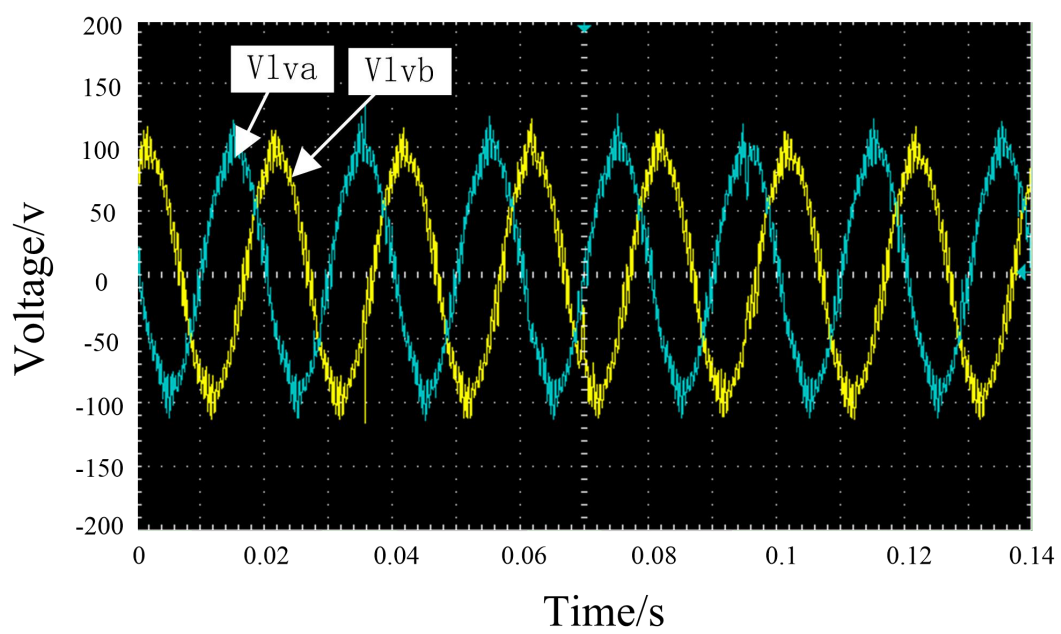

Fig. 19. LV grid voltages experimental waveform 


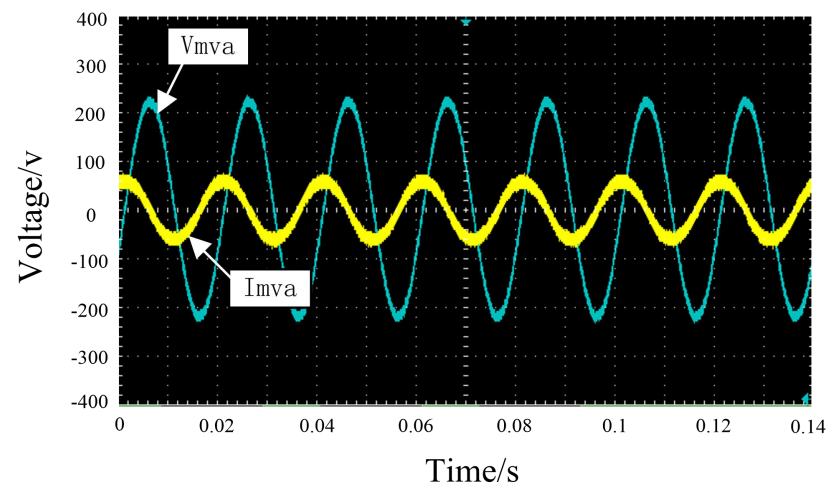

Fig. 20. The waveform of the MV voltages and MV grid current without power factor correction experimental waveform

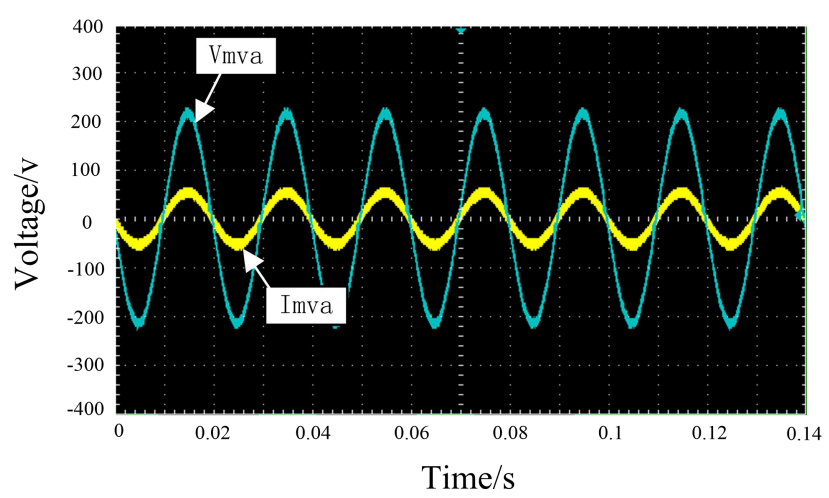

Fig. 21. The waveform of the MV voltages and MV grid current with power factor correction experimental waveform

\section{Conclusion}

In this paper, proposed a current predictive control model for the matrix converter-based novel power electronic transformer. The control strategy takes input power factor and output current as control objects. According to the input and output filter circuit, the prediction model is built. The cost function is constructed by using the reference value and prediction value, and the switch combination which minimizes the cost function is applied to the matrix converter. In this control strategy, in order to control the output voltage, the PI regulator is added. The value of the difference between the reference voltage and the actual voltage is adjusted by the PI regulator, and the result as the reference value of the output current. According to the simulation and experimental waveform, it can be seen that the output 
voltage conforms to the reference value, and the input power factor is close to 1 . The result shows that the system model is constructed correctly and the control method is used properly.

\section{References}

[1] J. Saha, A. Ayad and R. Kennel, "Direct model predictive current control for matrix converters," 2017 International Conference on Nascent Technologies in Engineering (ICNTE), Navi Mumbai, 2017, pp. 1-5.

[2] G. Zhang, J. Yang, Y. Sun, M. Su, Q. Zhu and F. Blaabjerg, "A Predictive-ControlBased Over-Modulation Method for Conventional Matrix Converters," in IEEE Transactions on Power Electronics, vol. 33, no. 4, pp. 3631-3643, April 2018.

[3] J. Lei et al., "Predictive Power Control of Matrix Converter With Active Damping Function," in IEEE Transactions on Industrial Electronics, vol. 63, no. 7, pp. 4550-4559, July 2016.

[4] S. F. Pinto, P. Alcaria, J. Monteiro and J. F. Silva, "Matrix Converter-Based Active Distribution Transformer," in IEEE Transactions on Power Delivery, vol. 31, no. 4, pp. 1493-1501, Aug. 2016.

[5] M. Vijayagopal, P. Zanchetta, L. Empringham, L. De Lillo, L. Tarisciotti and P. Wheeler, "Modulated model predictive current control for direct matrix converter with fixed switching frequency," 2015 17th European Conference on Power Electronics and Applications (EPE'15 ECCE-Europe), Geneva, 2015, pp. 1-10.

[6] F. V. Lima, S. F. Pinto and J. F. Silva, "Power electronics voltage regulators for distribution transformers," 4th International Conference on Power Engineering, Energy and Electrical Drives, Istanbul, 2013, pp. 1362-1367.

[7] O. Gulbudak and E. Santi, "FPGA-Based Model Predictive Controller for Direct Matrix Converter," in IEEE Transactions on Industrial Electronics, vol. 63, no. 7, pp. 4560-4570, July 2016.

[8] M. Siami, D. A. Khaburi, M. Rivera and J. Rodríguez, "An Experimental Evaluation of Predictive Current Control and Predictive Torque Control for a PMSM Fed by a Matrix Converter," in IEEE Transactions on Industrial Electronics, vol. 64, no. 11, pp. 84598471, Nov. 2017. 
[9] M. Rivera et al., "A Comparative Assessment of Model Predictive Current Control and Space Vector Modulation in a Direct Matrix Converter," in IEEE Transactions on Industrial Electronics, vol. 60, no. 2, pp. 578-588, Feb. 2013.

[10] M. Rivera, C. Rojas, J. Rodriguez and J. Espinoza, "Methods of source current reference generation for predictive control in a direct matrix converter," in IET Power Electronics, vol. 6, no. 5, pp. 894-901, May 2013.

[11] L. Tarisciotti et al., "Modulated Predictive Control for Indirect Matrix Converter," in IEEE Transactions on Industry Applications, vol. 53, no. 5, pp. 4644-4654, Sept.-Oct. 2017.

[12] M. Vijayagopal, L. Empringham, L. de Lillo, L. Tarisciotti, P. Zanchetta and P. Wheeler, "Current control and reactive power minimization of a direct matrix converter induction motor drive with Modulated Model Predictive Control," 2015 IEEE International Symposium on Predictive Control of Electrical Drives and Power Electronics (PRECEDE), Valparaiso, 2015, pp. 103-108.

[13] H. Dan, Q. Zhu, T. Peng, S. Yao and P. Wheeler, "Preselection algorithm based on predictive control for direct matrix converter," in IET Electric Power Applications, vol. 11, no. 5, pp. 768-775, 52017.

[14] M. Hamouda, F. Fnaiech, K. Al-Haddad and H. Y. Kanaan, "Matrix converter control: a sliding mode approach," 30th Annual Conference of IEEE Industrial Electronics Society, 2004. IECON 2004, 2004, pp. 2295-2300 Vol. 3.

[15] J. Zhang, L. Li, Z. Malekjamshidi and D. G. Dorrell, "Predictive voltage control of direct matrix converter with reduced number of sensors for the renewable energy and microgrid applications," 2017 IEEE Energy Conversion Congress and Exposition (ECCE), Cincinnati, OH, 2017, pp. 3309-3315.

[16] O. Gulbudak, E. Santi and J. Marquart, "Finite state model predictive control for $3 \times 3$ matrix converter based on switching state elimination," 2014 IEEE Energy Conversion Congress and Exposition (ECCE), Pittsburgh, PA, 2014, pp. 5805-5812. 